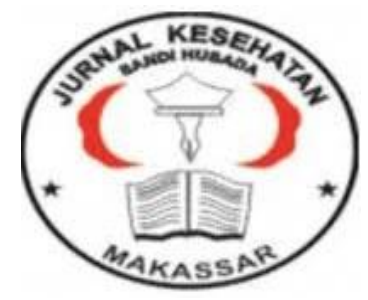

Jurnal Ilmiah Kesehatan Sandi Husada

hhttps://akper-sandikarsa.e-journal.id/JIKSH

Volume 9, Nomor 2, Desember 2020, pp 1044-1050

p-ISSN: 2354-6093 dan e-ISSN: 2654-4563

DOI: $10.35816 /$ jiskh.v10i2.459

\title{
Gaya Hidup dan Pola Makan Terhadap Kejadian Hipertensi \\ Literature Review
}

Lifestyle and Diet Patterns to the Occurance of Hypertension

\author{
Yessi Aprillia
}

Fakultas Kedokteran, Universitas Lampung

\section{Artikel info}

Artikel history:

Received; Agustus 2020

Revised: September 2020

Accepted; Oktober 2020
Keywords:

Gaya Hidup;

Pola Makan;

Hipertensi;
Abstract. Hypertension or high blood pressure is a type of noncommunicable disease that is chronic and can cause complications in body organs such as the heart, kidney, brain, and eyes. Hypertension can cause blood pressure to rise beyond normal limits. In systolic blood pressure hypertension it can reach $\geq 140 \mathrm{mmHg}$ and diastolic blood pressure $\geq 90$ $\mathrm{mmHg}$. The purpose of this study is to know the lifestyle and diet that can be used to prevent hypertension. The analytical method used is through a literature review that contains a description of the theory, the results of previous studies with the focus of the appropriate and relevant topics. Library studies used are 20 articles from 2015 to 2020 with search using 1 database, namely Google Scholar. Keywords used include lifestyle, diet and hypertension. The results of previous studies showed a relationship between the lifestyles and diet of the incidence of hypertension

Abstrak. Hipertensi atau tekanan darah tinggi merupakan jenis penyakit tidak menular yang bersifat kronis dan dapat menyebabkan komplikasi pada organ tubuh seperti jantung, ginjal, otak dan mata. Hipertensi dapat menimbulkan tekanan darah naik melebihi batas normal. Pada hipertensi tekanan darah sistolik dapat mencapai $\geq 140 \mathrm{mmHg}$ dan tekanan diastolic $\geq$ mmHg. Tujuan dari penelitian ini yaitu mengetahui gaya hidup dan pola makan yang dapat digunakan untuk mencegah terjadinya penyakit hipertensi. Metode analisis yang digunakan yaitu melalui literature review yang berisi uraian mengenai teori, dan hasil penelitian sebelumnya dengan fokus topic yang sesuai dan relevan. Kajian pustaka yang digunakan berjumlah 20 artikel dari tahun 2015 - 2020 dengan pencarian menggunakan 1 database yaitu google scholar. Kata kunci yang digunakan antara lain gaya hidup, pola makan dan hipertensi. Hasil penelitian sebelumnya menunjukkan adanya hubungan antara gaya hidup dan pola makan terhadap kejadian hipertensi.

\section{Coresponden author:}

Email: yessiaprillia234@gmail.com

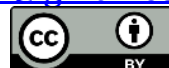

artikel dengan akses terbuka dibawah lisensi CC BY -4.0 


\section{Pendahuluan}

Hipertensi merupakan penyakit yang sering kita jumpai dimasyarakat sekitar dan penyakit ini sangat beresiko karena bisa menyebabkan komplikasi bagi penderitanya. Hipertensi atau tekanan darah tinggi adalah suatu keadaan dimana tekanan darah melewati batas normal sistolik $140 \mathrm{mmHg}$ atau lebih dan diastolik $90 \mathrm{mmHg}$ atau lebih pada 2 kali pengukuran dalam waktu selang 2 menit (Erdwin Wicaksana et al., 2019). Tekanan darah sistolik adalah tekanan darah yang terjadi pada saat jantung berkontraksi dan memompa darah keluar dari arteri sedangkan tekanan darah diastolik adalah tekanan darah pada saat jantung relaksasi dan mengisi darah kembali (Sumaryati, 2018). Tekanan darah sistolik dapat meningkat disebabkan oleh berkurangnya elastisitas pembuluh darah karena adanya penambahan usia sampai dekade ketujuh, sedangkan tekanan darah diastolik dapat meningkat sampai dekade kelima atau keenam dan bisa menetap atau menurun (Nuraini, 2015). Hipertensi termasuk salah satu faktor resiko yang berpotensi menimbulkan penyakit jantung dan pembuluh darah. Hipertensi sering tidak menunjukkan gejala bagi penderita dan baru disadari setelah adanya gangguan pada organ seperti organ jantung, otak dan ginjal (Fadhli, 2018). Tekanan darah yang tidak terkontrol dapat menimbulkan komplikasi, jika organ yang terkena jantung dapat menimbulkan penyakit gagal jantung kongestive, infark miokard, dan jantung koroner. Bila organ yang terkena otak maka penyakit yang bisa ditimbulkan seperti stroke, dan jika organ yang terkena adalah ginjal maka dapat terjadi gagal ginjal. Penyebab rusak nya organ tersebut diakibatkan oleh naiknya tekanan darah pada organ tersebut atau disebabkan karena adanya autoantibodi reseptor angiotensin II (Nuraini, 2015).

Hipertensi juga disebut sebagai penyakit silent killer dimana gejala yang sering ditimbulkan seperti sakit kepala, jantung berdebar - debar, rasa berat pada tengkuk, mudah lelah, pandangan kabur, telinga berdengung serta pada beberapa kasus pasien dapat terjadi perdarahan yang ditandai dengan mimisan (Azzahra, 2019). Organisasi Kesehatan Dunia (WHO) menyebutkan bahwa sekitar 972 juta jiwa di dunia atau 26,4\% orang menderita hipertensi. Dari 972 juta jiwa sebanyak 333 juta jiwa berada di negara maju dan 639 berada di negara berkembang (Kurniawan dan Sulaiman, 2019). Prevalensi hipertensi mencapai 34,1\% dengan angka tertinggi di provinsi kalimantan selatan 44,1\% dan yang terendah di provinsi papua sebesar 22,2\% (Adam, 2019). Menurut Kementrian Kesehatan tahun 2018 hipertensi menjadi peringkat pertama dari jenis penyakit tidak menular dengan jumlah kasus mencapai 185.857 (Kemenkes RI, 2019). Berdasarkan penyebabnya hipertensi dibagi menjadi 2 yaitu hipertensi primer dan hipertensi sekunder. Hipertensi primer atau istilah lain nya esensial adalah hipertensi yang tidak diketahui penyebabnya beberapa faktor resiko yang dapat mempengaruhi seperti usia, jenis kelamin, genetic, merokok, konsumsi garam, konsumsi lemak, aktivitas fisik dan obesitas. Sedangkan hipertensi sekunder yang penyebabnya dapat diketahui seperti adanya kelainan pembuluh darah pada ginjal, hipertiroid dan gangguan pada kelenjar adrenal (hiperaldosteroisme) (Nurhaedah, 2018).

Penelitian yang dilakukan oleh Kurniawan, I., dan Sulaiman dengan judul "Hubungan Olahraga, Stress dan Pola Makan dengan Tingkat Hipertensi di Posyandu Lansia di Kelurahan Sudirejo I Kecamatan Medan Kota" yang dilakukan dengan menggunakan penelitian survey analitik dengan metode cross sectional menunjukkan bahwa adanya hubungan yang signifikan antara olahraga, stress dan pola makan terhadap tingkat hipertensi. Penelitian lain yang dilakukan oleh Lontoh, Y., dan Sindi, S pada tahun 2019 yang berjudul "Hubungan Gaya Hidup Dengan Kejadian Hipertensi Pada Pasien Rawat Jalan Di Puskesmas Kombos Manado" dengan jumlah sampel sebanyak 45 responden menyatakan bahwa adanya hubungan antara gaya hidup dengan kejadian hipertensi. Dari 
hasil disebutkan bahwa responden yang melakukan aktivitas fisik sebanyak 16 orang dan yang tidak melakukan aktivitas fisik sebanyak 29 orang. Responden yang merokok sebanyak 8 orang dan tidak merokok 37 orang. Total responden yang menderita hipertensi grade 1 sebanyak 43 orang $(95,6 \%)$ dan hipertensi grade 2 sebanyak 2 orang $(4,4 \%)$ (Lontoh dan Sahentendi, 2019). Kemudian penelitian oleh Kadir Sunarto, 2019 dengan judul "Pola Makan Dan Kejadian Hipertensi" menyatakan bahwa sebanyak 24 responden dengan pola makan yang buruk, 20 responden mengalami prehipertensi, 13 responden terkena hipertensi derajat 1 , dan 7 responden terkena hipertensi derajat 2 (Kadir, 2019). Gaya hidup sehat merupakan salah satu cara untuk meminimalisir kejadian hipertensi yaitu dengan cara tidak merokok, aktivitas fisik yang cukup dan mengkonsumsi makanan yang bergizi. Karena hal itu penulis tertarik untuk melakukan literature review mengenai "Hubungan Gaya Hidup Dan Pola Makan Terhadap Kejadian Hipertensi" dengan tujuan untuk memberikan informasi dan pengetahuan kepada pembaca mengenai gaya hidup dan pola makan yang dapat mencegah untuk terjadinya hipertensi.

\section{Metode}

Metode yang digunakan yaitu literature review atau disebut juga tinjauan pustaka dengan cara memaparkan kembali materi yang sudah pernah di terbitkan kemudian meringkas topik pembahasan. Data yang digunakan dalam literature review ini yaitu berupa data sekunder yang diperoleh melalui hasil penelitian sebelumnya seperti buku, jurnal atau artikel pembelajaran lainnya dengan pencarian 1 database yaitu google scholar. Jumlah artikel yang digunakan dalam pembuatan literature review ini sebanyak 20 artikel dari tahun 2015 - 2020. Metode analisis yang digunakan yaitu systematic literature review dengan mengidentifikasi secara sistematis, mengkaji serta mengembangkan penelitian yang sebelumnya dengan topik yang relevan.

\section{Hasil Dan Pembahasan}

Hipertensi terkadang membuat penderita berbahaya karena hipertensi disebut juga sillent killer yang artinya tidak menimbulkan keluhan dan tidak disadari oleh penderita sehingga mudah untuk terjadinya komplikasi penyakit lainnya. Hipertensi dapat menyerang siapa saja baik dari kelompok umur, sosial, dan ekonomi (Poniyah, 2018). Salah satu penyebab hipertensi yaitu gaya hidup dan pola makan masyarakat, karena seiring berjalan nya waktu pengaruh globalisasi di semua bidang banyak sekali perubahan dimulai dari gaya hidup, pola makan bahkan aktivitas fisik yang berpengaruh terhadap meningkatnya penyakit tidak menular salah satunya yaitu hipertensi (Roza, 2016). Penelitian yang dilakukan oleh Wijaya, I., Rama, N.K.K., dan Hardianto, H dilakukan pada penelitian cross sectional study dan menggunakan simple random sampling dengan besar sampel 74 orang, 41 orang menderita hipertensi dan 33 orang tidak menderita hipertensi. Judul penelitian nya yaitu "Hubungan Gaya Hidup dan Pola Makan terhadap Kejadian Hipertensi diwilayah Kerja Puskesmas Towata Kabupaten Takalar" hasil dari penelitian ini menunjukkan bahwa terdapat hubungan kebiasaan merokok, mengkonsumsi garam dapur dan konsumsi makanan berlemak dengan kejadian hipertensi, sedangkan aktivitas fisik tidak ada hubungan yang signifikan (Wijaya et al., 2020).

Penelitian kedua yang dilakukan oleh Mahmudah, S., Taufik, M., Firlia, A.A., dan Ibnu, M pada tahun 2015 yang berjudul "Hubungan Gaya Hidup Dan Pola Makan Dengan Kejadian Hipertensi Pada Lansia Di Kelurahan Sawangan Baru Kota Depok Tahun 2015" menyatakan bahwa adanya hubungan antara aktivitas fisik, konsumsi lemak dan konsumsi natrium terhadap kejadian hipertensi (Mahmudah et al, 2015). Penelitian ketiga yang 
dilakukan oleh Widianto, A.A., Romadhoni, F.M., Karita Dewi., dan Purbowati, R.M tahun 2018 dengan judul "Hubungan Pola Makan Dan Gaya Hidup Dengan Angka Kejadian Hipertensi Pralansia Dan Lansia Di Wilayah Kerja Puskesmas I Kembaran" menyatakan bahwa terdapat hubungan pola makan dan gaya hidup terhadap kejadian hipertensi. Pola makan yang tidak baik dapat menimbulkan penyakit kardiovaskular yang salah satu nya adalah hipertensi (Widianto, A et al., 2018).

Penelitian keempat yang dilakukan oleh Alhuda, R.T., Pratiwi, S., dan Dewi, N pada tahun 2018 dengan judul "Hubungan Antara Pola Makan Dan Gaya Hidup Dengan Tingkatan Hipertensi Pada Middle Age 45 - 95 Tahun Di Wilayah Kerja Puskesmas Dinoyo Kota Malang" menyatakan bahwa dari jumlah sampel sebanyak 36 orang didapatkan hasil adanya hubungan antara pola makan dan gaya hidup terhadap tingkatan hipertensi (alhuda et al., 2018). Penelitian kelima yang dilakukan oleh dismiantoni, 2020 dengan judul "Hubungan Merokok dan Riwayat Keturunan Dengan Kejadian Hipertensi" menunjukkan hasil sebanyak 42 responden yang memiliki kebiasaan merokok 36 responden $(85,7 \%)$ diantara nya mengalami hipertensi. Penelitian ini memiliki nilai pvalue $=0,016$, hal ini menunjukkan adanya hubungan signifikan antara kebiasaan merokok dengan kejadian hipertensi (Dismiantoni, et al., 2020).

Dari hasil penelitian yang pertama Kebiasaan merokok merupakan salah satu faktor resiko yang dapat menyebabkan terjadinya hipertensi, karena rokok mengandung zat nikotin dan karbonmonoksida yang ketika dihisap zat tersebut masuk ke aliran darah dan dapat merusak pembuluh darah yang dapat menyebabkan aterosklerosis sehingga pembuluh darah menjadi menyempit dan menyebabkan tekanan dalam arteri meningkat. Zat lainnya yang terdapat dalam rokok yaitu karbon monoksida. Karbon monoksida yang ada di rokok jika terhisap maka akan mengalir ke darah dan menggantikan ikatan oksigen, sehingga jantung bekerja menjadi lebih keras lagi karena kebutuhan oksigen yang kurang. Hal ini mengakibatkan tingginya tekanan darah dalam tubuh (Furqani, et al., 2020).

Hipertensi merupakan salah satu penyakit yang tidak menular dan bersifat kronis, akan tetapi hipertensi bisa dicegah dengan pengaturan diet yang sesuai yaitu dengan cara mempertahankan berat badan ideal, menjaga pola makan (tidak mengkonsumsi lemak dan garam berlebihan) dan gaya hidup seperti tidak merokok, tidak mengkonsumsi alkohol, aktivitas fisik (olahraga) dengan rutin, mengatasi stress, dan memeriksakan tekanan darah rutin. Yang dimaksud dengan diet pada hipertensi yaitu mengatur pola makan dengan mengurangi kadar natrium, mengurangi konsumsi lemak dan memperbanyak konsumsi buah - buah, sayuran, biji - bijian dan makanan dengan kandungan kalsium, magnesium dan kalium yang tinggi. Dalam mengatur berat badan dapat dilakukan dengan cara melakukan gaya hidup dan pola makan yang baik seperti aktivitas fisik yang rutin dan membatasi asupan kalori. Disarankan agar pasien meminimalisir penggunaan bumbu penyedap makanan setiap kali memasak dan makanan yang sering dihangatkan. Bumbu penyedap masakan memiliki kandungan bahan kimia yang tidak baik untuk kesehatan sedangkan makanan yang dihangatkan terlalu sering dapat meningkatkan kadar kolesterol Low Density Lipoprotein (LDL) dalam darah sehingga dapat menyebabkan plak yang akan membuat pembuluh darah tersumbat dan peredaran darah tidak lancar (Sunarti et al., 2015).

Saat seseorang mengalami stress, sekresi katekolamin yang disintesis oleh medulla adrenal akan meningkat sehingga angiotensin, renin dan aldosteron pun ikut meningkat. Saraf simpatis akan ikut teraktivasi sehingga terjadi pelepasan hormon norepinefrin ke pembuluh darah. Hal ini dapat menyebabkan peningkatan curah jantung dan total 
peripheral resistance (TPR), jika terjadi secara berkepanjangan maka akan terjadi hipertrofi pada jantung dan pembuluh darah sehingga tekanan darah meningkat (Gunawan dan Adriani, 2020). Dari beberapa penelitian yang sudah dipaparkan diatas, hasil penelitian dari Wijaya pada tahun 2020 menyebutkan bahwa tidak ada hubungan yang signifikan antara aktivitas fisik terhadap kejadian hipertensi akan tetapi penelitian ini bertolak belakang dengan penelitian mahmudah, 2015. Selain pola makan aktivitas fisik juga merupakan salah satu cara penatalaksanaan dalam penyakit hipertensi. Olahraga yang disarankan yaitu seperti aerobik, jogging, senam, berenang dan juga bersepeda. Angkat beban tidak disarankan karena memicu tekanan yang tidak diperlukan bagi jantung dan pembuluh darah. Olahraga yang baik meliputi jenis olahraga, cara melakukan olahraga dan waktu melakukan olahraga. Jenis olahraga yang paling baik yaitu menyesuaikan kondisi pasien. Penyesuaian ini dilakukan agar menghindari cidera yang mungkin bisa terjadi pada pasien. Selanjutnya yaitu cara melakukan olahraga yaitu dengan adanya pemanasan, gerakan inti dan pendinginan. Pemanasan dapat dilakukan dalam rentan waktu 5 sampai 10 menit dengan gerakan seperti berjalan atau berlari santai. Gerakan inti dapatdilakukan 30 sampai 45 menit atau menyesuaikan fisik dan dilanjutkan dengan pendinginan yang berguna untuk memberikan waktu bagi otot dan sistem kardiovaskular mengatur zat hasil metabolisme dari kegiatan yang telah dilakukan. Yang terakhir adalah waktu olahraga. Waktu olahraga yang paling baik yaitu pada pagi hari atau sore hari karena pada waktu ini kondisi lingkungan lebih optimal sehingga tidak mengganggu proses pengeluaran panas dalam tubuh. Olahraga dapat dilakukan 3 sampai 5 kali perminggu secara teratur karena dapat mengurangi kekakuan pada pembuluh darah, meningkatkan daya tahan jantung dan paru - paru sehingga tekanan darah dapat segera stabil kembali (Putriastuti, 2016).

Konsumsi makanan dengan kadar lemak tinggi juga berpengaruh terhadap kejadian hipertensi. Konsumsi makanan dengan kadar lemak yang tinggi dapat meningkatkan kadar kolesterol terutama Low Density Lipoprotein (LDL). LDL ini akan menumpuk di dalam darah dan jika dibiarkan dalam waktu yang lama akan menimbulkan deposisi kolesterol dan kolesteril pada jaringan ikat dinding pembuluh darah arteri dan menjadi plak atau biasa disebut juga dengan aterosklerosis. Jika sudah terjadi aterosklerosis maka pembuluh darah akan kehilangan elastisitas nya sehingga aliran darah terganggu dan memicu peningkatan volume darah dan tekanan darah (Wijaya et al., 2020). Selain konsumsi lemak, konsumsi garam yang berlebihan juga merupakan salah satu faktor resiko lainnya untuk terjadinya hipertensi. Natrium memiliki peran dalam tubuh seperti merangsang fungsi saraf, pengaturan keseimbangan asam basa dalam darah, kontraksi otot serta mengatur tekanan osmosis agar cairan tidak keluar dari darah dan masuk ke sel (Furqani et al., 2020). Akan tetapi konsumsi natrium dalam jumlah yang berlebih akan berdampak negative pada kesehatan karena konsumsi natrium dalam jumlah berlebih dapat menyebabkan diameter pembuluh darah arteri mengecil sehingga jantung bekerja lebih keras untuk mendorong volume darah yang meningkat. Pengaruh konsumsi natrium yang berlebih juga dapat menyebabkan meningkatnya cairan dari sel yang berpindah konsentrasi yang rendah ke tinggi. Jika berlebihan dalam mengkonsumsi natrium makan cairan yang ada di ekstraseluler meningkat dan diikuti oleh volume darah yang ikut meningkat sehingga tekanan darah pun ikut naik (Saputra dan anam, 2016).

\section{Simpulan Dan Saran}

Penyakit hipertensi merupakan penyakit kardiovaskular yang bersifat kronis dan tidak dapat disembuhkan, akan tetapi hipertensi dapat dicegah dengan cara memperbaiki gaya hidup dan pola makan yang baik seperti mengkonsumsi makanan dengan kandungan garam dan lemak yang rendah, tidak merokok dan aktivitas fisik yang sesuai dengan kondisi tubuh. 


\section{Daftar Rujukan}

Adam, L. (2019). Determinan hipertensi pada lanjut usia. Jambura Health and Sport Journal, 1(2), 82-89.

Alhuda, Robin, T., Prastiwi, S., \& Dewi, N. (2018). Hubungan Antara Pola Makan Dan Gaya Hidup Dengan Tingkatan Hipertensi Pada Middle Age 45-59 Tahun Di Wilayah Kerja Puskesmas Dinoyo Kota Malang. Nursing News Journal, 3(1), 550-562.

Azzahra, S. S. (2019). Obstructive Sleep Apnea (OSA) Sebagai Faktor Resiko Hipertensi. Jurnal Ilmiah Kesehatan Sandi Husada, 10(2), 321-324. https://doi.org/10.35816/jiskh.v10i2.180.

Dismiantoni, N., Anggunan, Triswanti, N., \& Kriswiastiny, R. (2020). Hubungan Merokok Dan Riwayat Keturunan Dengan Kejadian Hipertensi. Jurnal Ilmiah Kesehatan Sandi Husada, 11(1), 30-36. https://doi.org/10.35816/jiskh.v10i2.214.

Erdwin Wicaksana, K., Surudarma, I. W., \& Wihandani, D. M. (2019). Prevalensi hipertensi pada orang dewasa menengah dengan overweight di denpasar tahun 2018. Intisari Sains Medis, 10(3), 821-824.https://doi.org/10.15562/ism.v10i3.490.

Fadhli, W. M. (2018). Hubungan Antara Gaya Hidup Dengan Kejadian Hipertensi Pada Usia Dewasa Muda Di Desa Lamakan Kecamatan Karamat Kabupaten Buol. Jurnal Kesma, $7(6), 1-14$.

Furqani, N., Rahmawati, C., \& Melianti, M. (2020). Hubungan Gaya Hidup Dengan Kejadian Hipertensi Pada Pasien Rawat Jalan di Puskesmas Pagesangan Periode Juli 2019. Lumbung Farmasi: Jurnal Ilmu Kefarmasian, 1(1), 34-40. https://doi.org/10.31764/lf.v1i1.1635.

Gunawan, S. P., \& Adriani, M. (2020). Hipertensi Pada Orang Dewasa Di Kelurahan Klampis Ngasem, Surabaya. Media Gizi Indonesia, 15(2), 119-126. https://doi.org/10.204736/ mgi.v15i2.119-126

Kadir, S. (2019). Pola Makan dan Kejadian Hipertensi. Jambura Health and Sport Journal, $1(2), 56-60$.

Kemenkes RI. (2019). Profil Kesehatan Indonesia 2018 [Indonesia Health Profile 2018]. Retrieved from:http://www.depkes.go.id/resources/download/pusdatin/profil-kesehatan indonesia/Data-dan-Informasi_Profil-Kesehatan-Indonesia-2018.pdf

Kurniawan, I., \& Sulaiman. (2019). Hubungan Olahraga , Stress dan Pola Makan dengan Tingkat Hipertensi di Posyandu Lansia di Kelurahan Sudirejo I Kecamatan Medan Kota. Journal of Health Science and Physiotherapy, 1(1), 10-17.

Lontoh, Y., \& Sahentendi, S. (2019). Hubungan Gaya Hidup Dengan Kejadian Hipertensi Pada Pasien Rawat Jalan Di Puskesmas Kombos Manado. Journal of Community and Emergency, 7(3), 365-377.

Mahmudah, S., Maryusman, T., Arini, F. A., \& Malkan, I. (2015). Hubungan Gaya Hidup Dan Pola Makan Dengan Kejadian Hipertensi Pada Lansia Di Kelurahan Sawangan Baru. Biomedika, 7(2), 43-51.

Nuraini, B. (2015). Risk Factors of Hypertension. Jurnal Majority, 4(5), 10-19. Retrieved from http://juke.kedokteran.unila.ac.id/index.php/majority/article/view/602/606

Nurhaedah. (2018). Studi Kasus Pada Keluarga Ny.'S' Dengan Hipertensi Dikelurahan Barombong Kecamatan Tamalate Kota Makassar. Jurnal Ilmiah Kesehatan Sandi Husada, 6(1), 1366-1374.https://doi.org/10.35816/jiskh.v6i1.18

Poniyah, S. (2018). Pada Lansia di Puskesmas Darussalam Medan. Jurnal Darma Agung, XXVI(1), 522-532.

Putriastuti, L. (2016). Analisis hubungan antara kebiasaan olahraga dengan kejadian hipertensi pada pasien usia 45 tahun keatas. Jurnal Berkala Epidemiologi, 4(2), 225236. 
Roza, Andalia. (2016). Hubungan Gaya Hidup Dengan Kejadian Hipertensi Di Puskesmas Dumai Timur Dumai-Riau. Jurnal Kesehatan STIKes Prima Nusantara Bukittinggi, 7(1), 47-52.

Saputra, 0., Anam, K. (2016). Gaya Hidup sebagai Faktor Risiko Hipertensi pada Masyarakat Pesisir Pantai. Majority, 5(3), 118-123.

Sumaryati, M. (2018). Studi Kasus Asuhan Keperawatan Gerontik Pada Keluarga Ny"M" Dengan Hipertensi Dikelurahan Barombong Kecamatan Tamalate Kota Makassar. Jurnal Ilmiah Kesehatan Sandi Husada, 6(2), 6-10. https://doi.org/10.35816/jiskh.v6i2.54.

Sunarti, Sunarno, I., \& Alvino. (2015). Upaya Penderita Hipertensi Untuk Mempertahankan Pola Hidup Sehat. Journal of Ners and Midwifery, 2(2), 120-125. https://doi.org/ 10.26699/jnk.v2i2.art.p120-125.

Widianto, A, A., Romdhoni, F, M., Dewi, K., \& Purbowati, R, M. (2018). Hubungan Pola Makan Dan Gaya Hidup Dengan Angka Kejadian Hipertensi Pralansia Dan Lansia Di Wilayah Kerja Puskesmas I Kembaran. Jurnal unimus, 1(5), 58-67.

Wijaya, I., K, K. R. N., \& Haris, H. (2020). Hubungan Gaya Hidup dan Pola Makan terhadap Kejadian Hipertensi diwilayah Kerja Puskesmas Towata Kabupaten Takalar. Media Publikasi Promosi Kesehatan Indonesia, 3(1), 5-11. 